\title{
New therapies for antiemetic prophylaxis for chemotherapy
}

\author{
Mellar P Davis, MD, FCCP, FAAHPM
}

Cleveland Clinic Lerner School of Medicine, Case Western Reserve University, and Taussig Cancer Institute, The Cleveland Clinic, Cleveland, Ohio

A number of new advances have occurred over the past 2 years in the management of chemotherapy-related nausea and vomiting (CINV). A new neurokinin-1 receptor antagonist (NKIRA), netupitant, has been combined with palonosetron in a single oral tablet for treating the effects of moderately emetogenic chemotherapy (MEC) and highly emetogenic chemotherapy (HEC). Rolapitant, another NK1RA, unlike aprepitant, has a long half-life and does not block CYP-3A4 and therefore has fewer drug interactions. Olanzapine reduces nausea more effectively than aprepitant in patients who are receiving HEC and is a better rescue antiemetic than is metoclopramide. Ginger lacks efficacy as an antiemetic agent for CINV. Although there was some evidence in a pilot study of gabapentin as an antiemetic, it was no better in reducing CINV than was placebo. Compliance to guidelines in multiple settings ranges from $50 \%-60 \%$ but is improved by computerized order entry of antiemetics and recommendations displayed with chemotherapy.

\section{$\mathrm{T}$} The presence of nausea, vomiting, and anorexia at the end of chemotherapy has a synergistic detrimental effect on patient quality of life and significantly diminishes the therapeutic benefit to palliative chemotherapy. ${ }^{1}$ Many patients present with anorexia, nausea, and vomiting before chemotherapy which, if untreated, will adversely affect the tolerance to palliative chemotherapy. ${ }^{1,2}$ There are multiple risk factors for emesis, including young age, female gender, lack of regular alcohol use, motion sickness, emesis during pregnancy, and a history of emesis with previous chemotherapy. ${ }^{3}$ Antiemetic guidelines have included only drug choices based on chemotherapy and emetogenic classification. Choices are based on whether a chemotherapeutic drug or drug combination is highly emetogenic (HEC), moderately emetogenic (MEC) or low emetogenic. Patient characteristics and their risks for emesis are not included in guidelines. Emesis has been the primary outcome in antiemetic drug trials. Risk is divided into 2 timeframes; acute (0-24 hours after chemotherapy) and delayed (25-120 hours after chemotherapy). Secondary endpoints include nausea and quality of life. ${ }^{3}$

Major advances in the management of chemotherapy-induced nausea and vomiting (CINV) occurred in 2003 when both palonosetron and aprepitant (APR) became commercially available. Palonosetron is the preferred serotonin receptor antagonist (5HT3RA) used for prophylaxis and is combined with APR and dexamethasone for HEC; ${ }^{4-8}$ palonosetron $0.25 \mathrm{mg}$ intravenously (IV) plus APR $125 \mathrm{mg}$ by mouth plus dexamethasone $20 \mathrm{mg}$ on Day 1, followed by $80 \mathrm{mg}$ of APR on days 2 and 3 and dexamethasone $8 \mathrm{mg}$ twice a day through days 2-4. The standard antiemetic prophylaxis for MEC is palonosetron $0.25 \mathrm{mg}$ IV or 0.5 $\mathrm{mg}$ by mouth plus dexamethasone $20 \mathrm{mg}$ on the day of chemotherapy only. Requirements for multiple antiemetics became evident clinically when 5HT3RAs were found to be ineffective after 24 hours. Mechanistically, substance $\mathrm{P}$ activation of neurokinin-1 receptors (NK1Rs) on vagal afferents, brainstem, and vomiting centers was found to be important in generating delayed emesis. ${ }^{9}$

Compliance to guidelines is a problem - a significant number of patients do not receive standard antiemetics. Patient factors that adversely affect compliance include the complexity of treatment prophylaxis for HEC, polypharmacy, mucositis, and depression. Physicians underestimate nausea and vomiting. Physician work load and poor communication between physician and patient further reduce compliance. ${ }^{6}$ As a step forward in an effort to reduce complexity of the treatment and improve compliance, the development of fosaprepitant eliminates days 2 and 3 of APR for HEC and for adriamycin plus cyclophosphamide (AC) chemotherapy used

Accepted for publication November 18, 2015. Correspondence: Mellar P Davis, MD, FCCP, FAAHPM; davism6@ccf.org. Disclosures: The author has no disclosures. JCSO 2016;14:11-20. @2016 Frontline Medical Communications. DOI 10.12788/jicso.0207. 


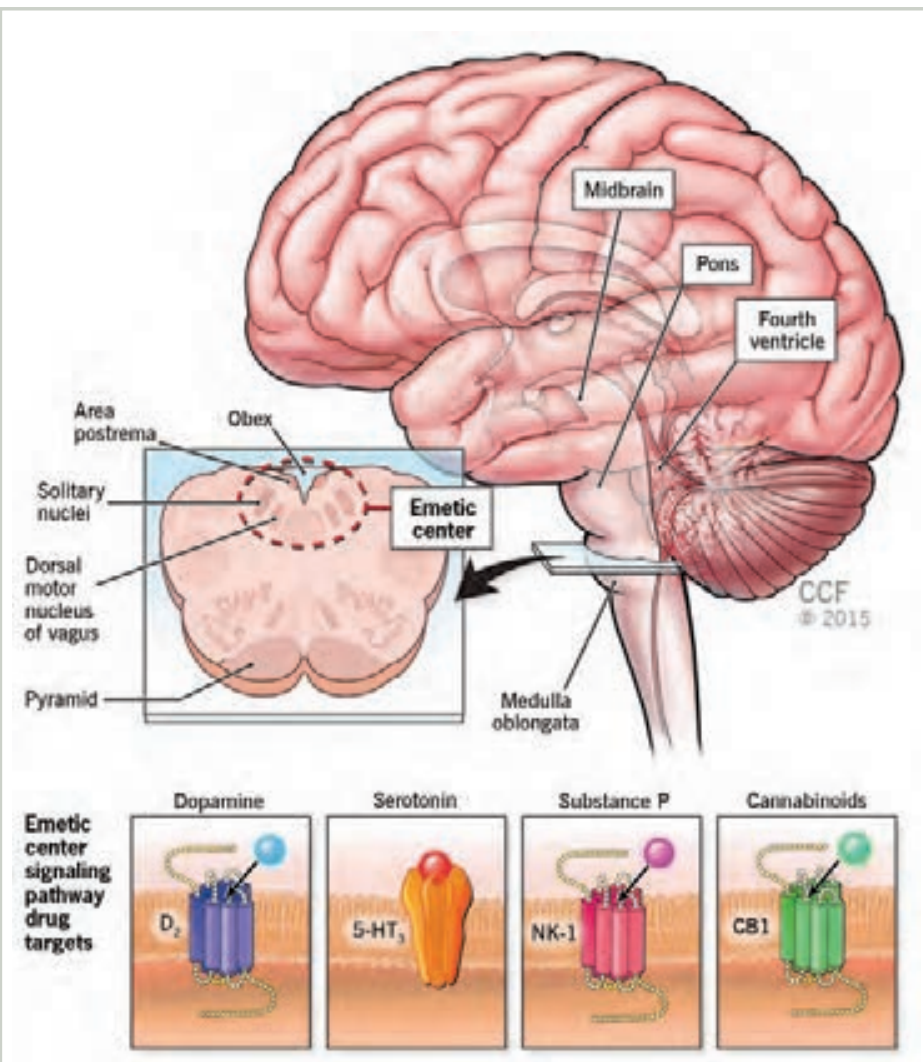

FIGURE 1 The emetic center consists of the circumventricular origin area posterior, nucleus tractus solitaries, and dorsal motor nucleus of the vagus. A central pattern generator located near the emetic center coordinates the emetogenic response. Multiple neurotransmitters are involved in generating emesis. Dopamine and serotonin are emetogenic. Substance $P$ is responsible for delayed chemotherapy nausea and vomiting. Cannabinoids block emesis through inhibition of serotonin-receptor responses.

for breast cancer. Fosaprepitant is an APR pro-drug which is converted to active drug by phosphatases. ${ }^{10}$

\section{Pathophysiology of CINV}

Multiple neurotransmitters are involved in generating vomiting. The pathways and neurotransmitters for nausea are less well understood. Prophylaxis is more successful in preventing emesis than nausea. Certain antiemetics are more successful than others in preventing nausea. ${ }^{11}$

In the vomiting reflex, cisplatin damages the gastrointestinal tract leading to calcium dependent exocytic release of serotonin $(5 \mathrm{HT})$ from enterochromaffin cells within mucosa. Serotonin binds to 5HT3 receptors on the dorsal vagal complex, which activate signals to the nucleus tractus solitarius (NTS) chemoreceptor trigger zone and central pattern generator. The chemoreceptor trigger zone releases multiple neurotransmitters which activate the central pattern generator. Efferent transmission goes to respiratory muscles, vasomotor areas, salivary centers, abdominal muscles, diaphragm, and esophagus. ${ }^{12,13}$ The NTS receives a convergence input, which is transmitted to the dorsal vagus complex as the common efferent pathway. ${ }^{13}$

Besides serotonin, dopamine, substance $\mathrm{P}$, histamine, and acetylcholine are involved in the vomiting reflex. These neurotransmitters are located on the dorsal vagal complex, area postrema, and gastrointestinal tract. ${ }^{12}$ Dopamine is found within the chemoreceptor trigger zone. Substance $\mathrm{P}$, which binds to neurokinin-1 (NK1) receptors, is located (colocated) with serotonin in the gastrointestinal tract and can be found in the NTS and area postrema. The NK1 pathway parallels the serotonin pathway, and substance $\mathrm{P}$ is largely responsible for delayed nausea. ${ }^{9}$ Substance $\mathrm{P}$ within enterochromaffin cells is released with serotonin substance P, crosses the blood-brain barrier, and binds to NK1 receptors within the NTS. ${ }^{14,15}$

The symptom cluster of malaise and anorexia caused by cisplatin is not mediated through 5HT3 or NK1 receptors and will not respond to standard antiemetics. Cisplatin activates glutamate receptors in the dorsal vagal complex, lateral parabrachial nucleus, and central nucleus of the amygdala. In animal models, $\mathrm{N}$-methyl-d-aspartate receptor antagonists reverse cisplatin anorexia and weight loss. ${ }^{16,17}$

The unique pharmacology of palonosetron involves interactions with NK1 receptors and unlike other 5HT3 receptors, palonosetron up-regulates protein kinase $\mathrm{C}$ activity while internalizing 5 HT 3 receptors. Protein kinase C phosphorylates NK1 receptors, which down-regulates NK1 receptor expression and allows the NK1 receptor antagonist netupitant to successfully compete with substance $\mathrm{P}$ for the remaining NK1 receptors. ${ }^{18}$

Cisplatin also increases calcium flux through L-type calcium changes. Nifedipine, an L-type calcium channel blocker, has a broad antiemetic activity in the least shrew; low-dose nifedipine potentiates the antiemetic activity of palonosetron. ${ }^{19}$ This needs to be explored clinically.

The antiemetic mechanism to corticosteroids is not well understood. Several mechanisms have been proposed. Dexamethasone reduces CNS levels of tryptophan, a precursor to serotonin. Corticosteroid anti-inflammatory activity reduces serotonin release from the gastrointestinal tract. Corticosteroids block production of prostaglandins and leukotrienes, which are involved in emetogenesis, and blunt the stress responses and cortisol-releasing hormone. Recent evidence suggests the corticosteroids enhance endocannabinoid and cannabinoid receptor expression within the dorsal vagus complex and stomach. ${ }^{20,23}$

\section{Therapies for CINV \\ Palonosetron}

Palonosetron is unique among the 5HT3RAs in part because of its long half-life and greater affinity for the 5HT3 receptor relative to first-generation 5HT3RAs. However, this does not explain palonosetron's unique 
benefits in reducing delayed emesis. ${ }^{24}$ If this were true, then repeated doses of a first-generation 5HT3RA would have made up for palonosetron's long half-life. Palonosetron allosterically binds to $5 \mathrm{HT} 3$ receptors and increases palonosetron affinity for the receptor (called positive cooperativity), which is unlike the bimolecular binding characteristics of first-generation 5HT3RAs. Palonosetron uniquely triggers $5 \mathrm{HT} 3$ receptor internalization. This unique $5 \mathrm{HT} 3$ receptor interaction inhibits substance $\mathrm{P}$-mediated responses. ${ }^{24-26}$ As demonstrated in multiple trials, palonosetron has better acute and delayed emesis prophylaxis for patients on HEC and MEC than do first-generation 5HT3RAs. ${ }^{27-29}$

\section{Netupitant}

Netupitant is a new oral NK1 receptor antagonist (NK1RA). It is rapidly absorbed and metabolized by cytochrome P450 (CYP-3A4) and type II (conjugase) hepatic enzymes. It is largely excreted in the hepatobiliary system (85\%), with less than $5 \%$ cleared by the kidneys, which makes it safe for use in patients with renal failure. Its pharmacokinetics are influenced by liver disease and altered by hepatic metastases. ${ }^{30,31}$ Netupitant's half-life is long - 90 hours - in contrast to APR, whose half-life is $9-13$ hours. ${ }^{32}$ Doses of $100 \mathrm{mg}, 200 \mathrm{mg}$, and $300 \mathrm{mg}$ result in an NK1 receptor occupancy of more than $90 \%$ as measured by PET scan imaging, which correlates with plasma level therapeutic levels of $225 \mathrm{ng} / \mathrm{mL}$. Netupitant is selective for NK1 receptors and does not bind to NK2 or NK3 receptors. ${ }^{31}$

Although netupitant does not interfere with palonosetron clearance, it is a moderate inhibitor of CYP-3A4. Ketoconazole area under the curve (AUC) plasma levels are increased by $140 \%$ in the presence of netupitant, by $144 \%$ with midazolam, and with dexamethasone by $72 \%$ on Day 1 and $138 \%$ on Day 4, ${ }^{33,34}$ which is why dexamethasone doses are reduced when NEPA is used. CYP-3A4 inducers such as rifampicin reduce netupitant AUC by $83 \% .{ }^{33}$ There is a risk of drug interactions between netupitant and narrow therapeutic index drugs metabolized through CYP-3A4 such as methadone, midazolam, and oxycodone. ${ }^{35,36}$ Clinically important drug interactions depend on the therapeutic range of the substrate drug, the degree to which the substrate drug is metabolized by CYP-3A4, the inhibiting drug plasma levels and the duration of inhibition. ${ }^{37}$ AUC ratios (AUC with the inhibiting drug present over the AUC of the drug alone) are 5 when clinically relevant. ${ }^{37}$ Therefore, it is unlikely that most netupitant drug interactions will be clinically important.

\section{NEPA}

NEPA consists of netupitant $300 \mathrm{mg}$ and palonosetron 0.5 $\mathrm{mg}$ in a single oral NEPA capsule that significantly simplifies the management of HEC. ${ }^{38,39}$ There does seem to be a synergy between netupitant and palonosetron. In the least shrew, cisplatin causes significant emesis and down- stream activation of multiple kinases within the brainstem. These downstream effects include the activation of extracellular signal-regulated protein kinase 1 and 2 (ERK1/2), protein kinase $\mathrm{C}(\mathrm{PKC})$, and protein kinase $\mathrm{A}(\mathrm{PKA})$. NEPA almost completely prevents emesis from cisplatin in this animal model. Both drugs prevent PKA phosphorylation, but only the combination prevents the acute phase phosphorylation of PKC and reverses phosphorylation of ERK1/2 during the delayed phase of emesis (2047 hours). ${ }^{40}$ NEPA causes NK1 receptor internalization, which blunts substance $\mathrm{P}$ neurotransmission. ${ }^{41}$ An additional benefit to the combination is that there are no drug interactions between palonosetron and netupitant; neither prolongs the QTc interval. ${ }^{30}$

In a double-blind randomized trial, NEPA plus dexamethasone was compared with oral palonosetron $0.5 \mathrm{mg}$ plus dexamethasone for MEC. The primary outcome was complete remission (no emesis and no rescue antiemetics) in the delayed phase (hours 25-120). NEPA was superior to palonosetron plus dexamethasone with a numbers needed to treat (NNT) of 13.5 for the primary outcome. The NNT for complete protection (no emesis, no rescue antiemetics, and nausea $<25 \mathrm{~mm}$ on a $100-\mathrm{mm}$ visual analogue scale) was 17 , and for nausea overall was 18 . Side effects were mild and consisted of headaches (3\%) and constipation $(2.1 \%) .^{42}$

A 5-arm, randomized, double-blind, controlled trial of patients receiving HEC compared 3 different doses of NEPA (100 mg, $200 \mathrm{mg}$, and $300 \mathrm{mg}$ ) plus 4 days of dexamethasone with palonosetron $0.5 \mathrm{mg}$ plus dexamethasone in the fourth arm and ondansetron $32 \mathrm{mg}$, APR $125 \mathrm{mg}$ on Day 1,80 mg on days 2 and 3, and dexamethasone in the fifth arm. ${ }^{43}$ NEPA $300 / 0.5 \mathrm{mg}$ plus dexamethasone was superior to palonosetron plus dexamethasone, with an NNT of 7.6. For complete protection, NEPA was also superior, with an NNT of 7.6. NEPA was at least equivalent if not slightly better than ondansetron, APR, plus dexamethasone, with a complete protection of $83 \%$, compared with $78.4 \%$. In a third trial, NEPA benefits for patients who received MEC and HEC did not diminish over multiple cycles nor did side-effects increase. ${ }^{44}$

\section{Rolapitant}

Rolapitant is a new NK1RA that has been tested in phase 3 trials for patients who receive MEC and HEC and was approved by the US Food and Drug Administration in fall 2015. ${ }^{45-47}$ Unlike APR and netupitant, rolapitant does not inhibit CYP-3A4 and therefore has fewer drug interactions. It has a long half-life (180 hours), so it is given on the first day only of chemotherapy. Dexamethasone dose reductions are unnecessary, as is the case with NEPA. For those receiving MEC, rolapitant $200 \mathrm{mg}$ by mouth added to a 5HT3RA plus dexamethasone had an overall greater complete response compared with placebo $(68.6 \%$ 
vs $57.8 \% ; P<.001 ; \mathrm{NNT}=10)$. Complete protection was also greater with rolapitant $(62 \%$ vs $53.2 \% ; P=.001$; NNT = 11). The addition of oral rolapitant $200 \mathrm{mg}$ to a 5HT3RA plus dexamethasone in patients receiving at least $60 \mathrm{mg} / \mathrm{m}^{2}$ cisplatin significantly improved overall complete response (70.1\% vs $56.5 \% ; P=.001$; NT $=7.6)$ and significantly improved complete protection (71.6\% vs $63.0 \%$; $P=.037$; NNT $=11.6)$. A third trial involving patients on HEC found that the addition of rolapitant to a 5HT3RA and dexamethasone marginally improved overall complete remission $(67.5 \%$ vs $60.4 \% ; P=.084)$ and that nausea was better controlled with rolapitant $(55 \%$ vs $44 \% ; P=.009$; NNT $=9) \cdot{ }^{48,49}$

In a randomized pivotal trial, patients received granisetron $2 \mathrm{mg}$ orally and dexamethasone (20 mg orally) on Day 1 except for patients receiving taxanes who were given dexamethasone based on guidelines for taxanes and granisetron ( $2 \mathrm{mg}$ orally) on days 2 and 3 . Individuals were randomized to either oral rolapitant $180 \mathrm{mg}$ or placebo. Efficacy was based on a modified intention-to-treat population comprising patients who received at least 1 dose of study drug. The primary endpoint was the proportion of patients achieving a complete response (no emesis or use of rescue medication) in the delayed phase ( $>24-120$ hours after chemotherapy) in Cycle 1. A significantly greater proportion of patients on rolapitant had complete responses in the delayed phase compared with placebo-treated controls (475 [71\%] vs 410 [62\%], respectively; odds ratio, 1.6; $95 \%$ confidence index [CI], 1.2-2.0; $P=.0002)$. No serious adverse event was treatment-related, and no treatment-related, treatment-emergent adverse event resulted in death. ${ }^{46} \mathrm{~A}$ second pivotal study of similar design found that rolapitant significantly improved delayed nausea in patients receiving $\mathrm{HEC}$ compared with granisetron and dexamethasone alone. ${ }^{45}$

\section{Olanzapine}

Olanzapine is an atypical antipsychotic that blocks dopamine (D1, D2, D3, and D4), serotonin (5HT2a, 5HT2c, 5HT3, and 5HT6), alpha-1 adrenergic, acetylcholine (muscarinic), and histamine receptors. ${ }^{50-54}$ It does not inhibit cytochrome enzymes and hence has few drug interactions. ${ }^{55}$ Within the context of an observational trial, olanzapine at usual doses did not prolong the QTc interval; however with titration, QTc intervals can increase. ${ }^{56,57}$ Olanzapine combined with megestrol acetate has shown greater improvement in weight, appetite, nausea control, and cancer-related anorexia than megestrol acetate alone. ${ }^{58}$ In addition, it is superior to metoclopramide as a rescue antiemetic for CINV. ${ }^{59}$ Several smaller trials have added olanzapine to standard chemotherapy antiemetic prophylaxis. ${ }^{11,60-73}$

Doses in these studies ranged between 5-10 mg daily for 5 days. The combination of olanzapine, palonosetron, and dexamethasone has been compared with standard palonosetron, APR, and dexamethasone for patients receiving $\mathrm{MEC}$ and $\mathrm{HEC}$ in an open label study. Both regimens were effective in reducing emesis; however, olanzapine better controlled delayed nausea ( $87 \%$ vs $67 \%, \mathrm{NNT}=5)$ and overall nausea $(69 \%$ vs $38 \%$; NNT $=2.9) .{ }^{11} \mathrm{~A}$ recent double-blind, randomized, controlled trial in patients receiving MEC or HEC and standard 5HT3RA, APR, and dexamethasone prophylaxis, compared the addition of olanzapine $5 \mathrm{mg}$ for 5 days with placebo. The stringent criteria total control (no emesis, no rescue medications, and nausea $<5 \mathrm{~mm}$ on $100-\mathrm{mm}$ visual analog scale) was superior with the addition of olanzapine (59\% vs $23 \%$; NNT $=2.5$; $P=.03$ ); total protection (no nausea, no rescue medication, and nausea $<25 \mathrm{~mm}$ on $100-\mathrm{mm}$ visual analog scale) was also superior with olanzapine ( $86 \%$ vs $45 \%$; NNT = 2.4; $P=.009$ ); and complete response (no emesis, no rescue medication) was $100 \%$ with the addition of olanzapine and $64 \%$ on placebo (NNT $=2.7 ; P=.004) .{ }^{64}$ Larger studies are needed to confirm these results. However, the National Comprehensive Cancer Network has included olanzapine in it 2015 antiemetic guidelines (Table 1).

\section{Gabapentin}

Gabapentin has been added to a 5HT3RA plus dexamethasone combination in a pilot study and was subsequently tested in a randomized, controlled trial of patients on HEC. ${ }^{74}$ In that trial of 437 patients, half received gabapentin on days 1-5 after chemotherapy, and half received placebo. Both groups were given a 5HT3RA and dexamethasone, but not an NK1RA. There was no improvement in control of delayed nausea or vomiting with gabapentin compared with placebo ( $47 \%$ vs $41 \%$, respectively). The trial was flawed in that an NK1RA was not included in the standard antiemetics. ${ }^{75}$

\section{Ginger}

Ginger has been explored as an antiemetic largely for women receiving $\mathrm{AC}$ for breast cancer. In a randomized trial, $0.5 \mathrm{~g}, 1 \mathrm{~g}$ or $1.5 \mathrm{~g}$ of ginger was added to a 5HT3RA plus dexamethasone combination. There was a reduction in acute emesis with ginger - of note is that the 1.5-g dose was least effective. There was no benefit in the delayed phase. ${ }^{76,77}$ In a second trial, $1.5 \mathrm{~g}$ of ginger was added to granisetron plus dexamethasone. There was an improvement in acute nausea or vomiting. ${ }^{78}$ Present guidelines recommend an NK1RA be used in addition to 5HT3RA and dexamethasone for AC. Therefore this study should be repeated with an NK1RA.

\section{Metoclopramide: new regulations}

The European Medicines Agency in July 2013 recommended that metoclopramide be prescribed for short-term treatment (up to 5 days) and should be limited to $30 \mathrm{mg}$ a 
TABLE 1 Prophylactic antiemetics for highly emetogenic chemotherapy

\begin{tabular}{|c|c|c|c|c|c|}
\hline NCCN & ESMO & International & Asco & MASCC & JSCO \\
\hline \multicolumn{6}{|c|}{ Day 1} \\
\hline 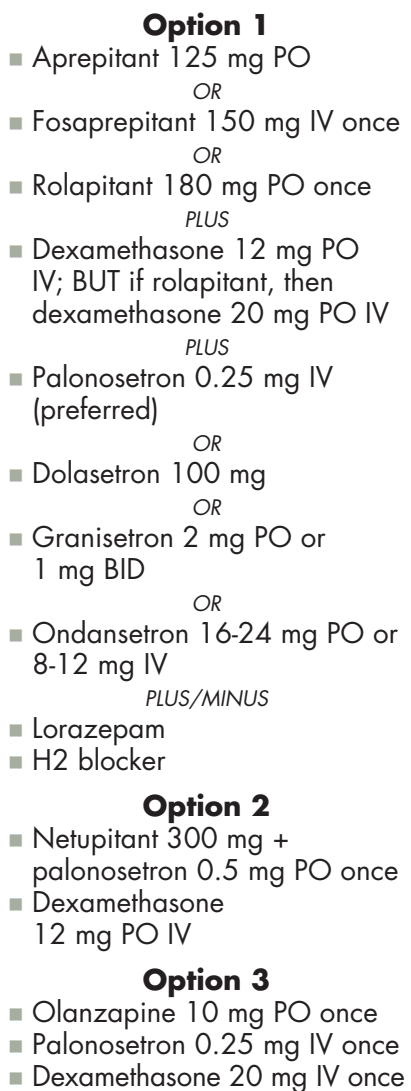 & 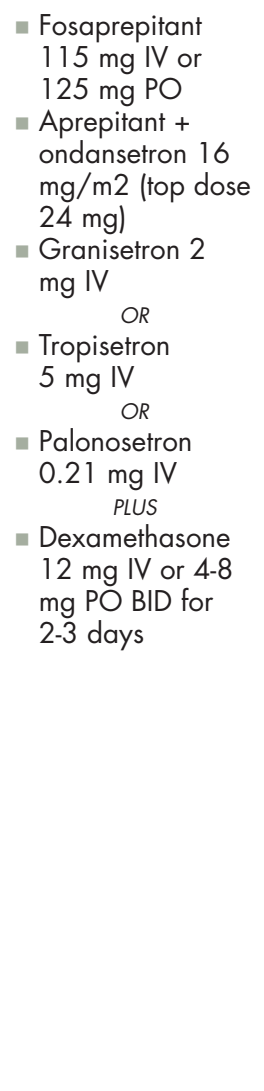 & 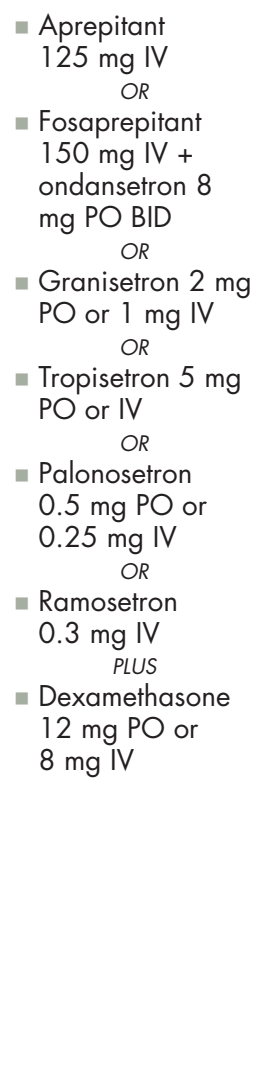 & 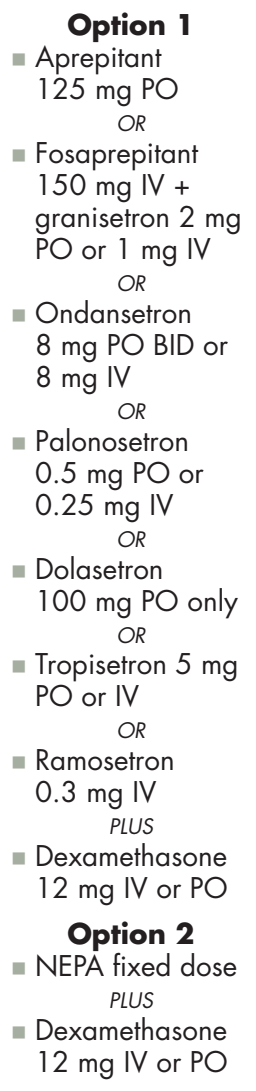 & 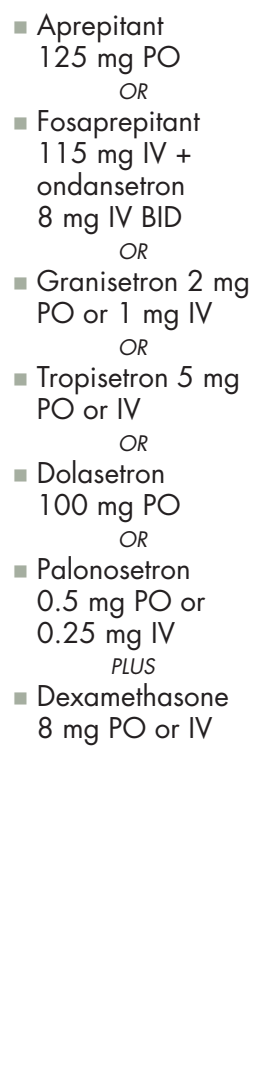 & \begin{tabular}{l} 
- Aprepitant \\
125 mg PO \\
\multicolumn{1}{c}{ OR } \\
- Fosaprepitant \\
150 mg IV \\
\multicolumn{1}{c}{ PLUS } \\
- 5 HT3 receptor \\
antagonist \\
lgranisetron or \\
palonosetron \\
or ramosetron \\
or ondansetron \\
or tropisetron \\
or azasetron or \\
indisetron) \\
Dexamethasone \\
9.9 mg IV
\end{tabular} \\
\hline \multicolumn{6}{|c|}{ Subsequent days } \\
\hline
\end{tabular}

\begin{tabular}{|c|c|c|c|c|c|}
\hline \multicolumn{6}{|c|}{ Rescue } \\
\hline 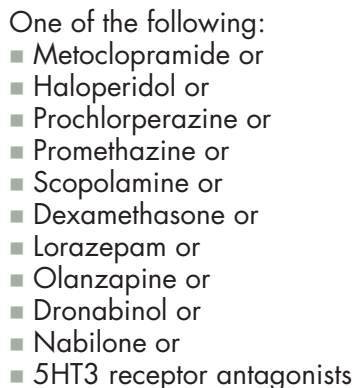 & $\begin{array}{l}\text { - Dopamine antag- } \\
\text { onists 3-4 times } \\
\text { a day } \\
\text { Metoclopramide } \\
20-30 \mathrm{mg} \text { PO } \\
\text { " Prochlorperazine } \\
\text { 10-20 mg PO } \\
\text { Domperidone } \\
20 \mathrm{mg} P O\end{array}$ & $\begin{array}{l}\text { Olanzapine } \\
10 \text { mg qhs } \\
\text { Metoclopramide } \\
10 \text { mg tid PO }\end{array}$ & $\begin{array}{l}\text { Add lorazepam } \\
\text { or alprazolam } \\
\text { OR } \\
\text { Olanzapine } \\
10 \mathrm{mg} / \mathrm{d} \\
\text { OR } \\
\text { High-dose meto- } \\
\text { clopramide }(2-3 \\
\mathrm{mg} / \mathrm{kg}) \text { substi- } \\
\text { tute for } 5 \mathrm{HT} 3 \\
\text { antagonists }\end{array}$ & 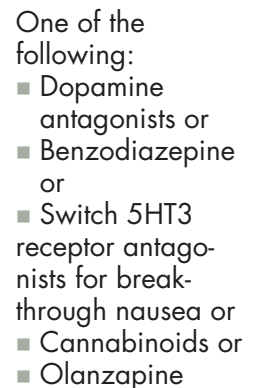 & 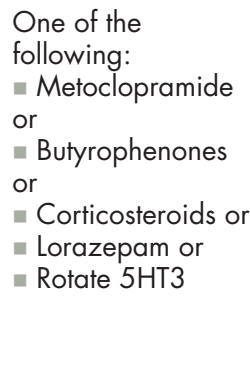 \\
\hline
\end{tabular}

5HT3, serotonin; ASCO, American Society of Clinical Cancer; BID, twice a day; ESMO, European Society for Medical Oncology; International, taken from a consensus document based on multiple international guidelines; IV, intravenously; JSCO, Japan Society of Clinical Oncology; MASCC, Multinational Association of Supportive Care in Cancer; NCCN, National Comprehensive Cancer Network; NEPA, netupitant 300 mg + palonosetron 0.5 mg; PO, by mouth; qhs, every night at bedtime 
TABLE 2 Prophylactic antiemetics for moderately emetogenic chemotherapy

NCCN

ESMO

International Day 1

Option 1

- Aprepitant $125 \mathrm{mg} \mathrm{PO}$ $O R$

- Fosaprepitant $150 \mathrm{mg} \mathrm{IV}$ once

- Rolapitant 180 mg PO once

PLUS

- Dolasetron 100 mg PO $O R$

- Granisetron 1-2 mg PO or 1 mg PO BID

$O R$

- Transdermal granisetron $34.3 \mathrm{mg} 24-48 \mathrm{~h}$ before chemotherapy

- Ondansetron 16-24mg PO or 8-12mg IV

$O R$

- Palonosetron $0.2 \mathrm{mg} \mathrm{IV} \pm$ Lorazepam 0.5-2 mg IV q4-6H $+/-\mathrm{H}_{2} 2$ blocker or PPI PLUS

- Dexamethasone 12 mg PO IV once

\section{Option 2}

- NEPA (netupitant $300 \mathrm{mg}$ plus palonosetron $0.5 \mathrm{mg}$ ) PO once

- Dexamethasone $12 \mathrm{mg}$ PO IV once

\section{Option 3}

- Olanzapine 10 mg PO once

- Palonosetron $0.25 \mathrm{mg}$ IV once

- Dexamethasone 20 mg IV once
For AC-related prophylaxis:

5HT3RAs dexamethasone, NKIRAs

For non-AC-related prophylaxis:

-5HT3RAs dexamethasone
For AC-related prophylaxis:

- 5HT3RAs,

dexamethasone, NKIRAs

For non-AC-related prophylaxis:

-5HT3RAs, dexamethasone (palonosetron preferred)

ASCO

MASCC

JSCO

For AC-related For AC-related prophylaxis:

-5HT3RAs,

dexamethasone, NKIRAs

For non-AC-related prophylaxis:

- Palonosetron

$0.25 \mathrm{mg}$

IV Day 1 , dexamethasone $20 \mathrm{mg}$ IV prophylaxis:

InT3RAs,

dexamethasone,

NKIRAs

For non-AC-related prophylaxis:

- Palonosetron

$0.25 \mathrm{mg} \mathrm{IV}$,

dexamethasone

$20 \mathrm{mg}$ IV
For prophylaxis related to carboplatin, ifosfamide, irinotecan, methotrexate:

- Aprepitant, dexamethasone, 5HT3RAs IV

Otherwise prophylaxis

5HT3RAs, dexamethasone

idexamethasone $20 \mathrm{mg}$ IV once

Subsequent days

- Aprepitant $80 \mathrm{mg}$ PO days 2-3

- Dolasetron 100 mg PO days 2-3

$O R$

- Granisetron 1-2 mg PO or

$1 \mathrm{mg}$ PO BID days 2-3 $O R$

- Ondansetron $8 \mathrm{mg} \mathrm{BID}$ or

$16 \mathrm{mg}$ days $2-3, \pm$ lorazepam

0.5-2 mg PO q4-6 hours, \pm

$\mathrm{H} 2$ blocker or PPI

= 5 HT3
monotherapy
days 2-3
OR
= Dexamethasone
$8 \mathrm{mg}$ PO IV days
$2-3 \quad$ OR
NK 1RA plus
steroid -
fosaprepitant
and rolapitant
Day 1 only,
aprepitant 80
mg days 2-3

prophylaxis:

For AC-related prophylaxis:

- Aprepitant \pm dexamethasone

- Aprepitant

days $2-3+$

dexamethasone

days $2-3$

or non-AC-related prophylaxis:

Dexamethasone $\pm 5 \mathrm{HT} 3 \mathrm{RAs}$

For non-AC-related prophylaxis:

- Dexamethasone days 2-3
For AC-related prophylaxis:

- Aprepitant days $2-3+$ dexamethasone days $2-3$

For non-AC-related prophylaxis:

- Dexamethasone days 2-3

\section{For prophylaxis} related to carboplatin, ifosfamide, irinotecan, methotrexate:? For prophylaxis related to carboplatin, ifosfamide, irinotecan, methotrexate:

- Aprepitant days 2-3

+ dexamethasone days $2-4$

Otherwise prophylaxis

- Dexamethasone days 2-4

\begin{tabular}{|c|c|c|c|c|c|}
\hline \multicolumn{6}{|c|}{ Rescue } \\
\hline $\begin{array}{l}\text { Same as high emetogenic } \\
\text { prophylaxis breakthrough }\end{array}$ & $\begin{array}{l}\text { Same as high } \\
\text { emetogenic } \\
\text { prophylaxis } \\
\text { breakthrough }\end{array}$ & $\begin{array}{l}\text { Same as high } \\
\text { emetogenic } \\
\text { prophylaxis } \\
\text { breakthrough }\end{array}$ & $\begin{array}{l}\text { Same as high } \\
\text { emetogenic } \\
\text { prophylaxis } \\
\text { breakthrough }\end{array}$ & $\begin{array}{l}\text { Same as high } \\
\text { emetogenic } \\
\text { prophylaxis } \\
\text { breakthrough }\end{array}$ & $\begin{array}{l}\text { Same as high } \\
\text { emetogenic } \\
\text { prophylaxis } \\
\text { breakthrough }\end{array}$ \\
\hline \multicolumn{6}{|c|}{$\begin{array}{l}\text { 5HT3, serotonin; AC, anthracycline + cyclophosphamide; ASCO, American Society of Clinical Cancer; BID, twice a day; ESMO, European Society for Medical Oncology; } \\
\text { International, from a consensus document based on multiple international guidelines; IV, intravenously; JSCO, Japan Society of Clinical Oncology; MASCC, Multinational } \\
\text { Association of Supportive Care in Cancer; NCCN, National Comprehensive Cancer Network; NK1RA, neurokinin-1 receptor antagonist; PO, by mouth; PPI, proton pump inhibitor; } \\
\text { qhs, every night at bedtime }\end{array}$} \\
\hline
\end{tabular}


TABLE 3 Prophylactic antiemetics for low emetogenic chemotherapy

\begin{tabular}{|c|c|c|c|c|c|}
\hline NCCN & ESMO & International & Asco & MASCC & JSCO \\
\hline \multicolumn{6}{|c|}{ Day 1} \\
\hline 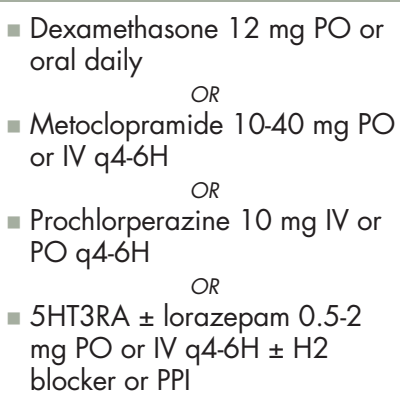 & $\begin{array}{l}\text { No routine } \\
\text { prophylaxis }\end{array}$ & $\begin{array}{l}\text { Dexamethasone } 8 \\
\text { mg PO IV }\end{array}$ & $\begin{array}{l}\text { Dexamethasone } 8 \\
\text { mg PO IV }\end{array}$ & $\begin{array}{l}\text { - Dexamethasone } \\
O R \\
\text { - 5HT3RAs } \\
O R \\
\text { - Dopamine } \\
\text { receptor } \\
\text { antagonists }\end{array}$ & $\begin{array}{l}\text { Dexamethasone } 6.6 \\
\mathrm{mg} \mathrm{IV}\end{array}$ \\
\hline
\end{tabular}

\begin{tabular}{|c|c|c|c|c|c|}
\hline \multicolumn{6}{|c|}{ Rescue } \\
\hline $\begin{array}{l}\text { Same as highly emetogenic } \\
\text { prophylaxis breakthrough }\end{array}$ & $\begin{array}{l}\text { Same as highly } \\
\text { emetogenic } \\
\text { prophylaxis } \\
\text { breakthrough }\end{array}$ & $\begin{array}{l}\text { Same as highly } \\
\text { emetogenic } \\
\text { prophylaxis } \\
\text { breakthrough }\end{array}$ & $\begin{array}{l}\text { Same as highly } \\
\text { emetogenic } \\
\text { prophylaxis } \\
\text { breakthrough }\end{array}$ & $\begin{array}{l}\text { Same as highly } \\
\text { emetogenic } \\
\text { prophylaxis } \\
\text { breakthrough }\end{array}$ & $\begin{array}{l}\text { Same as highly } \\
\text { emetogenic } \\
\text { prophylaxis } \\
\text { breakthrough }\end{array}$ \\
\hline \multicolumn{6}{|c|}{$\begin{array}{l}5 \mathrm{HT} 3 \text {, serotonin; AC, anthracycline + cyclophosphamide; ASCO, American Society of Clinical Cancer; BID, twice a day; ESMO, European Society for Medical Oncology; } \\
\text { International, from a consensus document based on multiple international guidelines; IV, intravenously; JSCO, Japan Society of Clinical Oncology; MASCC, Multinational } \\
\text { Association of Supportive Care in Cancer; NCCN, National Comprehensive Cancer Network; NK1RA, neurokinin-1 receptor antagonist; PO, by mouth; PPI, proton pump inhibitor; } \\
\text { qhs, every night at bedtime }\end{array}$} \\
\hline
\end{tabular}

day in adults. This was largely owing to the perceived risk of extrapyramidal disorders and tardive dyskinesia associated with long-term use of metoclopramide. The agency believed that the risks outweighed the benefits of metoclopramide in conditions that required long-term treatment.

\section{Current debates}

Should NK1RAs used with other platin derivatives?

Oxaliplatin is used to treat advanced colon cancer as well as other cancers. A randomized trial of 413 patients receiving oxaliplatin $85 \mathrm{mg} / \mathrm{m}^{2}$ within a FOLFOX regimen (folinic acid, fluorouracil, oxaliplatin) compared a 5HT3RA plus dexamethasone regimen with a 5HT3RA, dexamethasone, plus NK1RA regimen. Complete response (no vomiting, no antiemetic rescue) was better with the 3-drug regimen than with the 2-drug regimen (96\% vs $85 \%$, respectively). Complete protection (no vomiting, mild nausea at best) was also better with the 3 -drug regimen. ${ }^{79}$ There are a number of studies that have demonstrated that the emetogenic potential of carboplatin is greater than MEC, and that vomiting is reduced $10 \%-15 \%$ with the addition of an NK1RA to a 5HT3RA and dexamethasone. ${ }^{80-83}$

\section{How well are guidelines followed?}

Numerous guidelines for using antiemetic therapies have been developed and are available to guide prophylaxis (Tables 1-3). In a community practice in the United States, compliance to antiemetic guidelines is $57 \%$. Patients who received antiemetics in accordance with guidelines had significantly less nausea and vomiting than those who did not (53\% vs 44\%, respectively; adjusted odds ratio, $1: 3 ; 95 \%$ CI, 1.07-1.69; $P=.037) .{ }^{84}$ Japanese investigators used insurance claims data for patients who received $\mathrm{MEC}$ or HEC to determine the rate of patients who were prescribed antiemetic drugs before and after the release of guidelines for antiemetics in 2010. They reported a gradual increase in the prescription rate for antiemetic drugs during the study 2005-2011 period, with the prescription rate for high emetic risk patients increasing from $81.1 \%$ before the guidelines to $95.5 \%$ after, and from $78.5 \%$ to $89.9 \%$, respectively, for patients with moderate emetic risk. ${ }^{85}$ Within a large hospital practice, compliance to guidelines was $59 \%$ for acute prophylaxis and 54\% for delayed prophylaxis. ${ }^{86}$ When computerized physician order entry is used for antiemetics compliance to guidelines increases to $97 \%$. ${ }^{87}$ Therefore, the best way to improve prophylaxis for CINV is to require computerized order entry which provides guidelines for antiemetics.

\section{Antiemetics for high-dose chemotherapy with stem-cell rescue}

The combination of ondansetron dexamethasone plus 3 days of aprepitant is superior to ondansetron plus dexamethasone (complete response, $82 \%$ vs $66 \% ; P<.001$ ).$^{88}$ In a randomized trial of patients with myeloma receiving high-dose melphalan, the 3-drug combination of granisetron (days 1-4), aprepitant (days 1-3), and dexamethasone (days 2-3) was superior to granisetron and dexamethasone alone (complete response, $58 \%$ vs $41 \% ; P=.0042$ ). No emesis occurred in $78 \%$ of the patients who received the 
3 -drug regimen, compared with $65 \%$ of those who received the 2-drug regimen $(P=.0036){ }^{89}$ Therefore, individuals receiving conditioning regimens for bone marrow transplant should receive a three drug combination. ${ }^{88,90-94}$

\section{Summary}

Patients who receive HEC, oxaliplatin, or carboplatin should receive prophylaxis with 5HT3RA, preferably palonosetron, dexamethasone, and an NK1RA. Both NEPA and rolapitant are oral NK1 receptor antagonists and are given only on Day 1 of chemotherapy and hence have an advantage over aprepitant and fosaprepitant (which is given on Day 1 only and requires IV administration). Rolapitant has the additional advantage of having fewer drug interactions. Individuals on $\mathrm{AC}$ chemotherapy should also receive

\section{References}

1. Pirri C, Bayliss E, Trotter J, et al. Nausea still the poor relation in antiemetic therapy? The impact on cancer patients' quality of life and psychological adjustment of nausea, vomiting and appetite loss, individually and concurrently as part of a symptom cluster. Supportive Care Cancer. 2013;21:735-748.

2. Lazenby JM, Saif MW. Palliative care from the beginning of treatment for advanced pancreatic cancer. JOP. 2010;11:154-157.

3. Navari RM. Management of chemotherapy-induced nausea and vomiting: focus on newer agents and new uses for older agents. Drugs. 2013;73:249-262.

4. Roila F, Hesketh PJ, Herrstedt J, et al. Prevention of chemotherapy- and radiotherapy-induced emesis: results of the 2004 Perugia International Antiemetic Consensus Conference. Ann Oncol. 2006;17:20-28.

5. Herrstedt J, Roila F, EGWG. Chemotherapy-induced nausea and vomiting: ESMO clinical recommendations for prophylaxis. Ann Oncol. 2008;19(suppl 2):ii110-112.

6. Grunberg S, Clark-Snow RA, Koeller J. Chemotherapy-induced nausea and vomiting: contemporary approaches to optimal management. Supp Care Cancer. 2010;18(suppl 1):S1-10.

7. Jordan K, Gralla R, Jahn F, Molassiotis A. International antiemetic guidelines on chemotherapy induced nausea and vomiting (CINV): content and implementation in daily routine practice. Eur J Pharmacol. 2014;722:197-202.

8. Kris MG, Tonato M, Bria E, et al. Consensus recommendations for the prevention of vomiting and nausea following high-emetic-risk chemotherapy. Supp Care Cancer. 2011;19(suppl 1):S25-32.

9. Diemunsch P, Grelot L. Potential of substance P antagonists as antiemetics. Drugs. 2000;60:533-546.

10. Navari RM. Fosaprepitant (MK-0517): a neurokinin-1 receptor antagonist for the prevention of chemotherapy-induced nausea and vomiting. Expert Opin Investig Drugs. 2007;16:1977-1985.

11. Navari RM, Gray SE, Kerr AC. Olanzapine versus aprepitant for the prevention of chemotherapy-induced nausea and vomiting: a randomized phase III trial. J Supp Oncol. 2011;9:188-195.

12. Hornby PJ. Central neurocircuitry associated with emesis. Am J Med. 2001;111(suppl 8A):106S-112S.

13. Hesketh PJ, Van Belle S, Aapro M, et al. Differential involvement of neurotransmitters through the time course of cisplatin-induced emesis as revealed by therapy with specific receptor antagonists. Eur J Cancer. 2003;39:1074-1080.

14. Freed AL, Audus KL, Lunte SM. Investigation of the metabolism of substance $\mathrm{P}$ at the blood-brain barrier using capillary electrophoresis with laser-induced fluorescence detection. Electrophoresis. 2001;22:3778-3784.

15. Tattersall FD, Rycroft W, Francis B, et al. Tachykinin NK1 receptor antagonists act centrally to inhibit emesis induced by the chemotherapeutic agent cisplatin in ferrets. Neuropharmacol. a 3-drug prophylaxis consisting of a 5HT3RA, an NK1RA, and dexamethasone, but only Day 1 dexamethasone NEPA will make prophylaxis easier to administer.

Patients who receive MEC should be treated with a 5HT3RA plus dexamethasone regimen. Rolapitant reduces the risk of drug interactions and is a single-dose NK1RA given by mouth. Olanzapine is the antiemetic of choice for patients with breakthrough nausea and vomiting. Metoclopramide is being limited in certain countries because of toxicity. At the present time, gabapentin does not seem to improve prophylaxis, although the randomized study to investigate that was flawed. Ginger may reduce acute but not delayed nausea and vomiting. Compliance to guidelines is $50 \%-60 \%$, but is improved with computerbased prescribing.

$1996 ; 35: 1121-1129$

16. Alhadeff AL, Holland RA, Nelson A, Grill HJ, De Jonghe BC. Glutamate receptors in the central nucleus of the amygdala mediate cisplatin-induced malaise and energy balance dysregulation through direct hindbrain projections. J Neuroscience. 2015;35:11094-11104.

17. De Jonghe BC, Horn CC. Chemotherapy agent cisplatin induces 48- $\mathrm{h}$ Fos expression in the brain of a vomiting species, the house musk shrew (Suncus murinus). Am J Physiol. 2009;296:R902-911.

18. Stathis M, Pietra C, Rojas C, Slusher BS. Inhibition of substance P-mediated responses in NG108-15 cells by netupitant and palonosetron exhibit synergistic effects. Eur J Pharmacol. 2012;689:25-30.

19. Darmani NA, Zhong W, Chebolu S, Vaezi M, Alkam T. Broadspectrum antiemetic potential of the L-type calcium channel antagonist nifedipine and evidence for its additive antiemetic interaction with the $5 \mathrm{HT}(3)$ receptor antagonist palonosetron in the least shrew (Cryptotis parva). Eur J Pharmacol. 2014;722:2-12.

20. Young SN. Mechanism of decline in rat brain 5-hydroxytryptamine after induction of liver tryptophan pyrrolase by hydrocortisone: roles of tryptophan catabolism and kynurenine synthesis. Br J Pharmacol. 1981;74:695-700.

21. Sagar SM. The current role of antiemetic drugs in oncology: a recent revolution in patient symptom control. Cancer Treat Rev. 1991;18:95-135.

22. Darmani NA, Ray AP. Evidence for a re-evaluation of the neurochemical and anatomical bases of chemotherapy-induced vomiting. Chem Rev. 2009;109:3158-3199.

23. Zheng Y, Wang XL, Mo FF, Li M. Dexamethasone alleviates motion sickness in rats in part by enhancing the endocannabinoid system. Eur J Pharmacol. 2014;727:99-105.

24. Rojas C, Raje M, Tsukamoto T, Slusher BS. Molecular mechanisms of $5 \mathrm{HT}(3)$ and $\mathrm{NK}(1)$ receptor antagonists in prevention of emesis. Eur J Pharmacol. 2014;722:26-37.

25. Navari RM. Palonosetron for the treatment of chemotherapyinduced nausea and vomiting. Future Oncol. 2014;15:2599-2608.

26. Rojas C, Thomas AG, Alt J, et al. Palonosetron triggers $5 \mathrm{HT}(3)$ receptor internalization and causes prolonged inhibition of receptor function. Eur J Pharmacol. 2010;626(2-3):193-199.

27. Botrel TE, Clark OA, Clark L, Paladini L, Faleiros E, Pegoretti B. Efficacy of palonosetron (PAL) compared to other serotonin inhibitors (5HT3R) in preventing chemotherapy-induced nausea and vomiting (CINV) in patients receiving moderately or highly emetogenic (MoHE) treatment: systematic review and meta-analysis. Supp Care Cancer. 2011;19:823-832.

28. Schwartzberg L, Barbour SY, Morrow GR, Ballinari G, Thorn MD, Cox D. Pooled analysis of phase III clinical studies of palonosetron versus ondansetron, dolasetron, and granisetron in the prevention of chemotherapy-induced nausea and vomiting (CINV). Supp Care Cancer. 2014;22:469-477. 
29. Popovic M, Warr DG, Deangelis C, et al. Efficacy and safety of palonosetron for the prophylaxis of chemotherapy-induced nausea and vomiting (CINV): a systematic review and meta-analysis of randomized controlled trials. Supp Care Cancer. 2014;22:1685-1697.

30. Spinelli T, Moresino C, Baumann S, Timmer W, Schultz A. Effects of combined netupitant and palonosetron (NEPA), a cancer supportive care antiemetic, on the ECG of healthy subjects: an ICH E14 thorough QT trial. Springerplus. 2014;3:389.

31. Spinelli T, Calcagnile S, Giuliano C, et al. Netupitant PET imaging and ADME studies in humans. J Clin Pharmacol. 2014;54:97-108.

32. Rizzi A, Campi B, Camarda V, et al. In vitro and in vivo pharmacological characterization of the novel NK(1) receptor selective antagonist netupitant. Peptides 2012;37:86-97.

33. Calcagnile S, Lanzarotti C, Rossi G, Henriksson A, Kammerer KP, Timmer W. Effect of netupitant, a highly selective NK(1) receptor antagonist, on the pharmacokinetics of palonosetron and impact of the fixed dose combination of netupitant and palonosetron when coadministered with ketoconazole, rifampicin, and oral contraceptives. Supp Care Cancer. 2013;21:2879-2887.

34. Lanzarotti C, Rossi G. Effect of netupitant, a highly selective NK(1) receptor antagonist, on the pharmacokinetics of midazolam, erythromycin, and dexamethasone. Supp Care Cancer. 2013;21:2783-2791.

35. Shiran MR, Lennard MS, Iqbal MZ, et al. Contribution of the activities of CYP3A, CYP2D6, CYP1A2 and other potential covariates to the disposition of methadone in patients undergoing methadone maintenance treatment. Br J Clin Pharmacol. 2009;67:29-37.

36. Soderberg Lofdal KC, Andersson ML, Gustafsson LL. Cytochrome P450-mediated changes in oxycodone pharmacokinetics/pharmacodynamics and their clinical implications. Drugs. 2013;73:533-543.

37. Loue C, Tod M. Reliability and extension of quantitative prediction of CYP3A4-mediated drug interactions based on clinical data. AAPS J. 2014;16:1309-1320.

38. Lorusso V, Karthaus M, Aapro M. Review of oral fixed-dose combination netupitant and palonosetron (NEPA) for the treatment of chemotherapy-induced nausea and vomiting. Future Oncol. 2015;11:565-577.

39. Navari RM. Profile of netupitant/palonosetron (NEPA) fixed dose combination and its potential in the treatment of chemotherapyinduced nausea and vomiting (CINV). Drug Des Devel Ther. 2015;9:155-161.

40. Darmani NA, Zhong W, Chebolu S, Mercadante F. Differential and additive suppressive effects of 5HT3 (palonosetron)- and NK1 (netupitant)-receptor antagonists on cisplatin-induced vomiting and ERK1/2, PKA and PKC activation. Pharmacol Biochem Behav. 2015;131:104-111.

41. Thomas AG, Stathis M, Rojas C, Slusher BS. Netupitant and palonosetron trigger NK1 receptor internalization in NG108-15 cells. Exp Brain Res. 2014;232:2637-2644.

42. Aapro M, Rugo H, Rossi G, et al. A randomized phase III study evaluating the efficacy and safety of NEPA, a fixed-dose combination of netupitant and palonosetron, for prevention of chemotherapyinduced nausea and vomiting following moderately emetogenic chemotherapy. Ann Oncol. 2014;25:1328-1333.

43. Hesketh PJ, Rossi G, Rizzi G, et al. Efficacy and safety of NEPA, an oral combination of netupitant and palonosetron, for prevention of chemotherapy-induced nausea and vomiting following highly emetogenic chemotherapy: a randomized dose-ranging pivotal study. Ann Oncol. 2014;25:1340-1346.

44. Gralla RJ, Bosnjak SM, Hontsa A, et al. A phase III study evaluating the safety and efficacy of NEPA, a fixed-dose combination of netupitant and palonosetron, for prevention of chemotherapy-induced nausea and vomiting over repeated cycles of chemotherapy. Ann Oncol. 2014;25:1333-1339.

45. Rapoport BL, Chasen MR, Gridelli C, et al. Safety and efficacy of rolapitant for prevention of chemotherapy-induced nausea and vomiting after administration of cisplatin-based highly emetogenic chemotherapy in patients with cancer: two randomised, active-controlled, double-blind, phase 3 trials. Lancet Oncol. 2015;16:1079-1089.

46. Schwartzberg LS, Modiano MR, Rapoport BL, et al. Safety and efficacy of rolapitant for prevention of chemotherapy-induced nausea and vomiting after administration of moderately emetogenic chemo- therapy or anthracycline and cyclophosphamide regimens in patients with cancer: a randomised, active-controlled, double-blind, phase 3 trial. Lancet Oncol. 2015;16:1071-1078.

47. Rapoport B, Chua D, Poma A, Arora S, Wang Y, Fein LE. Study of rolapitant, a novel, long-acting, NK1 receptor antagonist, for the prevention of chemotherapy-induced nausea and vomiting (CINV) due to highly emetogenic chemotherapy (HEC). Supp Care Cancer. 2015;23:3281-3288.

48. Duffy RA, Morgan C, Naylor R, et al. Rolapitant (SCH 619734): a potent, selective and orally active neurokinin NK1 receptor antagonist with centrally-mediated antiemetic effects in ferrets. Pharmacol Biochem Behav. 2012;102:95-100.

49. Gan TJ, Gu J, Singla N, et al. Rolapitant for the prevention of postoperative nausea and vomiting: a prospective, double-blinded, placebo-controlled randomized trial. Anesth Analg. 2011;112:804-812.

50. Fulton B, Goa KL. Olanzapine. A review of its pharmacological properties and therapeutic efficacy in the management of schizophrenia and related psychoses. Drugs. 1997;53:281-298.

51. Bymaster F, Perry KW, Nelson DL, et al. Olanzapine: a basic science update. Br J Psychiatry Suppl. 1999;37:36-40.

52. Bymaster FP, Falcone JF, Bauzon D, et al. Potent antagonism of $5 \mathrm{HT}(3)$ and $5 \mathrm{HT}(6)$ receptors by olanzapine. Eur J Pharmacol. 2001;430:341-349.

53. Bymaster FP, Hemrick-Luecke SK, Perry KW, Fuller RW. Neurochemical evidence for antagonism by olanzapine of dopamine, serotonin, alpha 1-adrenergic and muscarinic receptors in vivo in rats. Psychopharmacol. 1996;124:87-94.

54. Bymaster FP, Nelson DL, DeLapp NW, et al. Antagonism by olanzapine of dopamine $\mathrm{D} 1$, serotonin2, muscarinic, histamine $\mathrm{H} 1$ and alpha 1-adrenergic receptors in vitro. Schizophr Res. 1999;37:107-122.

55. Bymaster FP, Calligaro DO, Falcone JF, et al. Radioreceptor binding profile of the atypical antipsychotic olanzapine. Neuropsychopharmacol. 1996;14:87-96.

56. Ozeki Y, Fujii K, Kurimoto N, et al. QTc prolongation and antipsychotic medications in a sample of 1017 patients with schizophrenia. Prog Neuropsychopharmacol Biol Psychiatry. 2010;34:401-405.

57. Suzuki Y, Sugai T, Ono S, et al. Changes in the metabolic parameters and QTc interval after switching from olanzapine to aripiprazole in Japanese patients with stable schizophrenia. J Clin Psychopharmacol. 2011;31:526-528.

58. Navari RM, Brenner MC. Treatment of cancer-related anorexia with olanzapine and megestrol acetate: a randomized trial. Supp Care Cancer. 2010;18:951-956.

59. Navari RM, Nagy CK, Gray SE. The use of olanzapine versus metoclopramide for the treatment of breakthrough chemotherapyinduced nausea and vomiting in patients receiving highly emetogenic chemotherapy. Supp Care Cancer. 2013;21:1655-1663.

60. Flank J, Thackray J, Nielson D, et al. Olanzapine for treatment and prevention of acute chemotherapy-induced vomiting in children: a retrospective, multi-center review. Pediatric Blood Cancer. 2015;62:496-501.

61. Fonte C, Fatigoni S, Roila F. A review of olanzapine as an antiemetic in chemotherapy-induced nausea and vomiting and in palliative care patients. Crit Rev Oncol Hematol. 2015;95:214-221.

62. Hocking CM, Kichenadasse G. Olanzapine for chemotherapyinduced nausea and vomiting: a systematic review. Supp Care Cancer. 2014;22:1143-1151.

63. Liu J, Tan L, Zhang H, et al. QoL evaluation of olanzapine for chemotherapy-induced nausea and vomiting comparing with 5HT3 receptor antagonist. Eur J Cancer Care (Engl). 2015;24:436-443.

64. Mizukami N, Yamauchi M, Koike K, et al. Olanzapine for the prevention of chemotherapy-induced nausea and vomiting in patients receiving highly or moderately emetogenic chemotherapy: a randomized, double-blind, placebo-controlled study. J Pain Sympt Manage. 2014; $47: 542-550$.

65. Nagashima K, Iwasa S, Yanai T, et al. A double-blind randomized phase II study of olanzapine $10 \mathrm{mg}$ versus $5 \mathrm{mg}$ for emesis induced by highly emetogenic chemotherapy. Japan J Clin Oncol. 2015;45:229-231.

66. Navari RM. Olanzapine for the prevention and treatment of chronic nausea and chemotherapy-induced nausea and vomiting. Eur J 
Pharmacol. 014;722:180-186.

67. Navari RM, Einhorn LH, Loehrer PJ, Sr., et al. A phase II trial of olanzapine, dexamethasone, and palonosetron for the prevention of chemotherapy-induced nausea and vomiting: a Hoosier oncology group study. Supp Care Cancer. 2007;15:1285-1291.

68. Navari RM, Einhorn LH, Passik SD, et al. A phase II trial of olanzapine for the prevention of chemotherapy-induced nausea and vomiting: a Hoosier Oncology Group study. Supp Care Cancer. 2005; 13:529-534.

69. Tan L, Liu J, Liu X, et al. Clinical research of olanzapine for prevention of chemotherapy-induced nausea and vomiting. J Exp Clin Cancer Res. 2009;28:131.

70. Vig S, Seibert L, Green MR. Olanzapine is effective for refractory chemotherapy-induced nausea and vomiting irrespective of chemotherapy emetogenicity. J Cancer Res Clin Oncol. 2014;140:77-82.

71. Wang SY, Yang ZJ, Zhang L. Olanzapine for preventing nausea and vomiting induced by moderately and highly emetogenic chemotherapy. Asian Pac J Cancer Prev. 2014;15:9587-9592.

72. Wang X, Wang L, Wang H, Zhang H. Effectiveness of olanzapine combined with ondansetron in prevention of chemotherapy-induced nausea and vomiting of non-small cell lung cancer. Cell Biochem Biophysics. 2015;72:471-473.

73. Wang XF, Feng Y, Chen Y, Gao BL, Han BH. A meta-analysis of olanzapine for the prevention of chemotherapy-induced nausea and vomiting. Scientific Reports. 2014;4:4813.

74. Cruz FM, de Iracema Gomes Cubero D, Taranto P, et al. Gabapentin for the prevention of chemotherapy- induced nausea and vomiting: a pilot study. Supp Care Cancer. 2012;20:601-606.

75. Barton DL, Thanarajasingam G, Sloan JA, et al. Phase III doubleblind, placebo-controlled study of gabapentin for the prevention of delayed chemotherapy-induced nausea and vomiting in patients receiving highly emetogenic chemotherapy, NCCTG N08C3 (Alliance). Cancer. 2014;120:3575-3583.

76. Ryan JL, Heckler CE, Roscoe JA, et al. Ginger (Zingiber officinale) reduces acute chemotherapy-induced nausea: a URCC CCOP study of 576 patients. Supp Care Cancer. 2012;20:1479-1489.

77. Walstab J, Kruger D, Stark T, et al. Ginger and its pungent constituents non-competitively inhibit activation of human recombinant and native 5HT3 receptors of enteric neurons. Neurogastroenterol Motil. 2013;25:439-447, e302.

78. Panahi Y, Saadat A, Sahebkar A, Hashemian F, Taghikhani M, Abolhasani E. Effect of ginger on acute and delayed chemotherapyinduced nausea and vomiting: a pilot, randomized, open-label clinical trial. Integr Cancer Ther. 2012;11:204-211.

79. Nishimura J, Satoh T, Fukunaga M, et al. Combination antiemetic therapy with aprepitant/fosaprepitant in patients with colorectal cancer receiving oxaliplatin-based chemotherapy (SENRI trial): a multicentre, randomised, controlled phase 3 trial. Eur J Cancer. 2015;51:1274-1282.

80. Ito Y, Karayama M, Inui N, et al. Aprepitant in patients with advanced non-small-cell lung cancer receiving carboplatin-based chemotherapy. Lung Cancer. 2014;84:259-264.

81. Kitazaki T, Fukuda Y, Fukahori S, et al. Usefulness of antiemetic therapy with aprepitant, palonosetron, and dexamethasone for lung cancer patients on cisplatin-based or carboplatin-based chemotherapy. Supp Care Cancer. 2015;23:185-190.
82. Nagata S, Yatera K, Tokuyama S, et al. [Evaluation of the antiemetic effect of aprepitant in lung cancer patients receiving carboplatin-based chemotherapy using the Functional Living IndexEmesis questionnaire]. Gan To Kagaku Ryoho. [Article in Japanese] 2014;41:335-339.

83. Choi CH, Kim MK, Park JY, et al. Safety and efficacy of aprepitant, ramosetron, and dexamethasone for chemotherapy-induced nausea and vomiting in patients with ovarian cancer treated with paclitaxel/ carboplatin. Supp Care Cancer. 2014;22:1181-1187.

84. Gilmore JW, Peacock NW, Gu A, et al. Antiemetic guideline consistency and incidence of chemotherapy-induced nausea and vomiting in US community oncology practice: INSPIRE Study. J Oncol Prac. 2014;10:68-74.

85. Okuyama A, Nakamura F, Higashi T. Prescription trends of prophylactic antiemetics for chemotherapy-induced nausea and vomiting in Japan. Supp Care Cancer. 2014;22:1789-1795.

86. Caracuel F, Munoz N, Banos U, Ramirez G. Adherence to antiemetic guidelines and control of chemotherapy-induced nausea and vomiting (CINV) in a large hospital. J Oncol Pharm Prac. 2015;21:163-169.

87. Kadakia KC, Leal AD, Seisler DK, et al. Antiemetic prescribing practices using a computerized physician order entry system. Supp Care Cancer. 2014;22:217-223.

88. Stiff PJ, Fox-Geiman MP, Kiley K, et al. Prevention of nausea and vomiting associated with stem cell transplant: results of a prospective, randomized trial of aprepitant used with highly emetogenic preparative regimens. Biol Blood Marrow Transplant. 2013;19:49-55, e41.

89. Schmitt T, Goldschmidt H, Neben K, et al. Aprepitant, granisetron, and dexamethasone for prevention of chemotherapy-induced nausea and vomiting after high-dose melphalan in autologous transplantation for multiple myeloma: results of a randomized, placebo-controlled phase III trial. J Clin Oncol. 2014;32:3413-3420.

90. Bechtel T, McBride A, Crawford B, et al. Aprepitant for the control of delayed nausea and vomiting associated with the use of high-dose melphalan for autologous peripheral blood stem cell transplants in patients with multiple myeloma: a phase II study. Supp Care Cancer 2014;22:2911-2916.

91. Bubalo JS, Cherala G, McCune JS, Munar MY, Tse S, Maziarz R. Aprepitant pharmacokinetics and assessing the impact of aprepitant on cyclophosphamide metabolism in cancer patients undergoing hematopoietic stem cell transplantation. J Clin Pharmacol. 2012;52:586-594.

92. Deauna-Limayo D, Aljitawi OS, Ganguly S, Abhyankar S, Wick JA, McGuirk JP. Combined use of multiday palonosetron with aprepitant and low-dose dexamethasone in prevention of nausea and emesis among patients with multiple myeloma and lymphoma undergoing autologous hematopoietic stem cell transplant: a pilot study. J Oncol Pharm Prac. 2013;20:263-269.

93. Uchida M, Ikesue H, Miyamoto T, et al. Effectiveness and safety of antiemetic aprepitant in Japanese patients receiving high-dose chemotherapy prior to autologous hematopoietic stem cell transplantation. Biol Pharm Bull. 2013;36:819-824.

94. Uchida M, Kato K, Ikesue H, et al. Efficacy and safety of aprepitant in allogeneic hematopoietic stem cell transplantation. Pharmacother. 2013;33893-901. 